\title{
Changing balances in Dutch higher education
}

\author{
LEO C.J. GOEDEGEBUURE \& DON F. WESTERHEIJDEN \\ Center for Higher Education Policy Studies, University of Twente. The Netherlands
}

\begin{abstract}
Like many other higher education systems in the Western world, Dutch higher education underwent profound changes during the last decade. In this article we will present an overview of these changes, and try to formulate an analytical framework that might be suited to analyze this process. In order to set the stage, we will begin with an overview of the Dutch higher education system, in which the broad structure is described, and some trends are presented. Next, an overview is given of the retrenchment and restructuring operations with which Dutch higher education was confronted during the last decade. Drawing, mainly, on public administration and political theory, we then attempt to formulate a framework for analysis. In this we focus on the Dutch higher education system as a policy network, and address the relationships that exist between the various key actors in the network: between government and higher education, among higher education institutions themselves, and among the different actors within the institutions, especially administrators and acadernics. In doing so, we hope to demonstrate that at all these levels some identical basic processes operate which to a large extent determine the outcomes of governmental policies aimed at changing the higher education system.
\end{abstract}

Time and again the modern state stumbles over the academic system (Clark 1983:137)

\section{Higher education in the Netherlands}

\section{The Dutch higher education system: structure and trends}

Within the Dutch higher education system three types of institutions can be discerned: universities, institutes for higher vocational education (HBO), and the Open University. In the Netherlands, with around 15 million people, there are 13 universities, $86 \mathrm{HBO}$-institutions, all located throughout the country, and an Open University (distance education) in the south of the Netherlands, with 18 regional study centres dispersed throughout the country. As the Open University, because of its special nature, was not involved in the higher education policies which are considered in this article, no further attention shall be paid to it.

All higher education institutions in the Netherlands are funded largely by government, the additional resources coming from teaching, research and services such as consultancy, performed for third parties. All institutions operate within the legal and funding framework set up by government. To further clarify the operation of the Dutch higher education system, some more detailed comments can be made regarding funding and student enrolment. 


\section{Funding}

Within Dutch higher education, three 'flows of funds' are discerned. The first flow of funds is the direct funding of institutions through government. Most of the governmental funding through this flow is based on normative models for universities and for HBO-institutions, the main difference being that the HBOmodel does not contain a research component, as fundamental research is not considered a task for these vocationally oriented institutions. The principles underlying both models can be stated as follows (Ministry of Education and Science 1988: 44):

- a normative relationship between duties and funds, from which funding rules are defined;

- application of these rules produces a total amount (lump sum) which enables an institution to perform those activities which are funded by the government;

- institutions are free to spend this lump sum as they wish, on condition that the agreed upon activities are carried out in a fitting manner.

The central elements in the models are the number of students and, in the case of the universities, the volume of the so-called 'conditionally funded research', a nonstudent based allocation of research funds in which projects are initially funded for five years after which continuation is dependent on the quality assessment made by experts in their respective field. Although the total volume of conditionally funded research is fixed nationwide for 'many years ahead', allocation amongst institutions can alter because of the outcomes of the assessment procedure. The second flow of funds is the funding of university research through an autonomous research organization (NWO), an intermediate body, since it receives its resources from government as well. Most of the projects funded through this second flow involve doctorate research. The third flow of funds is the funds generated by the institutions for contract/third party research. In 1986 the ratios for the three flows were: $62 \%$ first flow, $16 \%$ second flow, and $22 \%$ third flow, on a total of 11,241 full time equivalent staff units (Ministry of Education and Science 1989: 199). At the moment the funding system is under review. One of the most important changes suggested is the separation of teaching and research funding, equalizing the governmental teaching expenditure for both universities and $\mathrm{HBO}$, and the allocation of research funds on a competitive basis through NWO (see De Vries 1990).

Government funding for higher education has declined over the last decennium. As can be seen from Table 1, actual public expenditure has remained more or less

Table 1. Public expenditure on higher education in million Dfl. (constant prices; $1975=100$ )

\begin{tabular}{rrrrrrrrr}
\hline 1975 & 1980 & 1981 & 1982 & 1983 & 1984 & 1985 & 1986 & 1987 \\
\hline 5,011 & 5,649 & 5,349 & 5,310 & 5,311 & 5,019 & 4,863 & 4,953 & 4,787 \\
100 & 113 & 107 & 106 & 110 & 97 & 99 & 96 & \\
\hline
\end{tabular}

Source: Kaiser et al. 1991. 
Table 2. Public expenditure per student in Dfl. by university and non-university sector (prices 1975)

\begin{tabular}{rrrrrrrrr}
\hline 1975 & 1980 & 1981 & 1982 & 1983 & 1984 & 1985 & 1986 & 1987 \\
\hline 18,706 & 15,336 & 14,942 & 14,133 & 13,441 & 12,519 & 11,993 & 12,052 & 11,566 \\
100 & 82 & 80 & 76 & 72 & 67 & 64 & 64 & 62 \\
& & & & & & & & \\
12,353 & 12,388 & 11,464 & 11,283 & 11,324 & 10,885 & 10,799 & 11,190 & 10,208 \\
100 & 100 & 93 & 91 & 92 & 88 & 87 & 91 & 83 \\
\hline
\end{tabular}

Source: Kaiser et al. 1991.

stable over the years, but no compensation has been made to cater for the increase in student numbers (Table 2).

\section{Student enrolment}

In the Netherlands, every student has the right to enrol as a student at either a university or an HBO-institution for 6 years, provided he/she meets the standard entry requirement of a secondary school diploma (see Figure 1). In 1988 some 165,000 students were enrolled in university education, while some 220,000 students (including part-time) followed higher education in the $\mathrm{HBO}$-sector. The right of

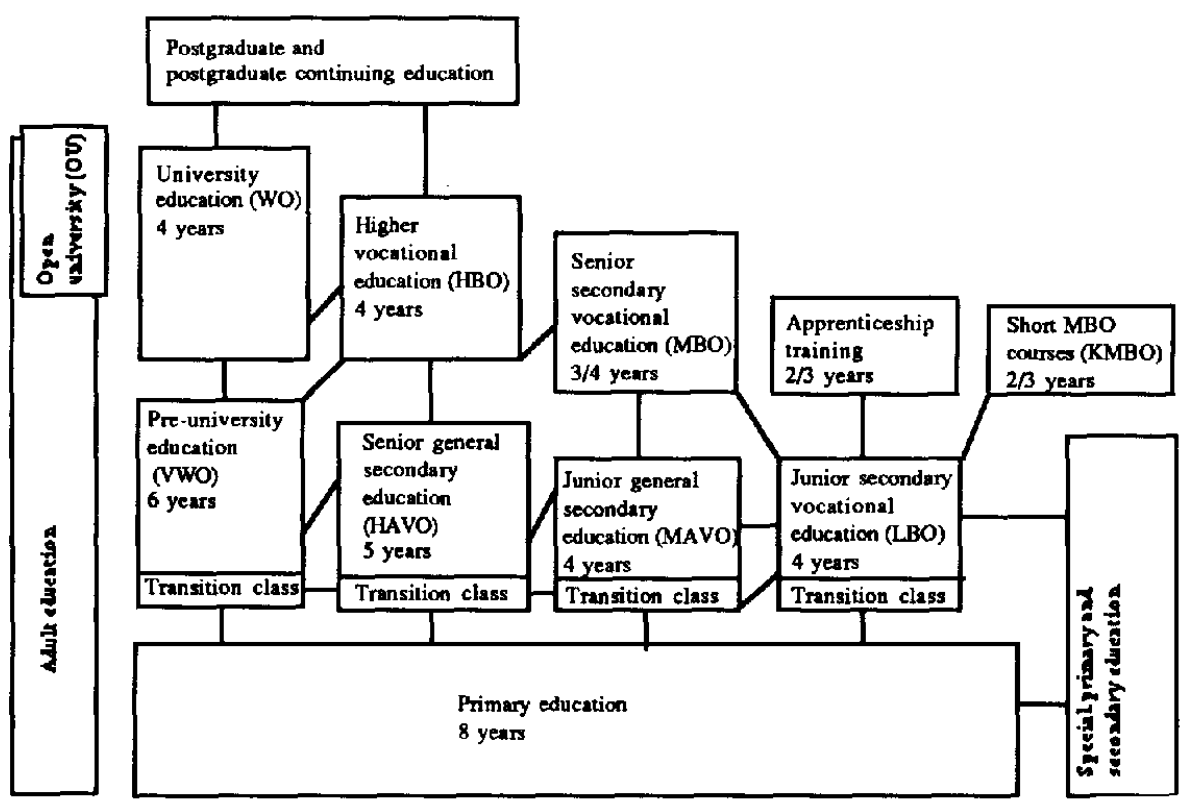

Fig. I. The Dutch education system. 
admission to higher education for everyone is a result of one of the principal objectives of Dutch higher education policy, namely to provide "higher education for the many'. There are a limited number of courses for which a numerus clausus applies, either based on capacity within the universities or on labour market conditions. Every student is entitled to a basic grant provided by the government. Within the system, provisions are made for loans and supplementary grants, depending on parental income. In principle, only students under 30 years of age can obtain these grants and loans.

Enrolments have increased steadily throughout most of the $1980 \mathrm{~s}$ in both sectors of the system, and have exceeded original estimates. In combination with the existing grant system, this is creating at present substantial budgetary problems for the government, despite the apparent reduction in terms of expenditure per student. We will return to this when discussing the recent policy developments in the Netherlands.

\section{Policy change in Dutch higher education: restructuring and reform}

As stated above, during the 1980 s higher education policy in the Netherlands underwent some profound changes. Basically, a distinction can be made between two types of policy change: the 'corrective' governmental policy initiatives that prevailed during the first half of the decennium, and the 'option supplying' policies that evolved during the second half. Especially the first type of policies has been geared towards increasing efficiency in the system. The latter type of policies relates to the introduction of a new 'steering philosophy' for higher education. However, since the often far-reaching and penetrating reforms and retrenchment operations during the late 1970 s and early 1980s have left their mark on higher education, specifically with respect to the way the institutions perceive governmental action, a brief overview of these policies is called for.

\section{Corrective reforms and retrenchment}

The main thrust of the major reform and retrenchment operations that occurred during the eighties was directed at the universities. In 1981 the Two Tier Act passed through parliament, restructuring university education. The objectives were to increase efficiency, stimulate shorter programmes, increase programme diversity and student choice, decrease actual duration of studies, stimulate planning and monitoring of study-load, and integrate university and HBO-education. These objectives were to be attained through the introduction of a 'first tier' with a four year duration, a limitation of the enrolment time-period to six years and the introduction of a 'second tier' in which selected students could follow specialized courses and research fellowships. At present, it appears that the objectives have only partly been reached (Bijleveld 1989).

The introduction of the two tier structure was followed by a major retrenchment 
operation in 1981, Task Reallocation and Concentration (TVC), in order to reduce the costs of the university sector, stimulate co-operation between disciplinary locations, concentrate research activities, and prevent further disintegration. The cuts amounted to a total of Dfl. 258 million. Although this retrenchment operation has been only a partial success (Boorsma and Koelman 1986; De Groot and Ritzen 1988; Van Vught 1985), it has left its mark on Dutch academia, especially because it was the first time severe budget cuts were carried through. In 1986 another retrenchment operation, Selective Contraction and Expansion (SKG), was forced on the universities. The TVC-operation was primarily efficiency-driven, without explicit reference to quality. The SKG-operation, as is indicated by the inclusion of 'selective', tried to use quality arguments in the implementation of the budget-cuts.

With respect to the research activities of universities, the government in 1983 introduced the system of Conditional Funding (CF) with the objectives of increasing accountability, promoting quality, and improving university research policy. The $\mathrm{CF}$-system brought about several changes in research funding. First, the institutional funding mechanism shifted from an enrolment-based system to a system based on norms and criteria, including those of scientific quality and societal relevance. Second, a system of quality assessment was introduced. Research programmes had to be approved by external bodies before they could be included in the CF-system. The results of the quality assessment processes were to be used for reallocation of budgets amongst the universities. When the system was introduced, the idea was to develop it on a basis of 'learning by doing': experiences gained would be used to further refine and adapt the system, so that in a number of years it would grow towards its final form. One of the main changes made in this process has been the replacement of ex ante quality assessments by ex post assessments. In effect, the introduction of the CF-system has been the first attempt to introduce a formal system of quality assessment in Dutch higher education. Although the system is currently under review because it did not fully meet the government's expectations in identifying excellent from good research, it has resulted in the acceptance of external assessment by the academic community (Bijleveld and Goedegebuure 1989; Spaapen et al. 1988). However, quality first really appeared on the higher education agenda as a policy issue during the latter part of the $1980 \mathrm{~s}$, with the introduction of a new steering philosophy by the Minister of Education and Science.

\section{A new governmental steering philosophy}

One of the criticisms that can be made regarding the retrenchment and restructuring operations described above, probably is that they were all ad hoc, sometimes even contradictory. In short, an overall policy framework was lacking, and the major underlying factor was budgetary constraint. Since 1985 a more encompassing and general policy framework has emerged, with the respective publications of the Higher Education: Autonomy and Quality document (HOAK 1985), the Higher Education and Research Plans (HOOP 1988, 1990) and the Higher Education and Research-bill (WHW 1988). 
In the HOAK-document, a new steering philosophy as presented by the minister, was deemed necessary because:

many in and around the higher education system are of the opinion that the present administrative and legislative higher education mechanism can no longer be considered optimal to meet the future demands which have to be placed on the system (Ministry of Education and Science 1985: 9).

The central concept of the philosophy is a substantial increase in the autonomy of the institutions through abolishing regulations, combined with the introduction of a system of retrospective quality control. This concept is the result of a departmental analysis of the existing policy instruments by which government has been steering the higher education system. This analysis showed that:

- control is not general enough and the units with which it is concerned are too small;

- partly for this reason, a number of instruments does not work as well as it might;

- insufficient justice is done to the institution's own responsibilities, particularly regarding teaching; and

- quality control and testing have not taken on a definite form (Ministry of Education and Science 1988: 23).

By granting institutions more autonomy, the minister strives towards a situation in which institutions themselves, through direct interaction with societal sub-systems, can react to the signals they receive, translating these into institutional policymaking. Necessary conditions for this are, amongst others, a strong and effective institutional management. The HOAK-document pictures a new image of administrative thought and action. Institutions are required to operate more in accordance with market developments and be more professional. Attention is focused on profiles, increases in performance and graduation rates, a diversified student supply, and better adjustment of course supply in relation to labour market demands. In order to facilitate these shifts in institutional behaviour, governmental steering will no longer be directed at the discipline level, but at a more aggregate level of 'sectors' of several disciplines. Governmental interference below the sector level is limited to the following grounds:

- if macro-efficiency would be harmed, i.e., if the introduction by an institution of a new course in a subject for which the capacity already far exceeded the demand, would constitute a waste of resources;

- if the course was clearly of sub-standard quality; or

- if it could not reasonably be considered as falling into one of the assigned sectors (e.g., starting a medical course within the law sector) (Ministry of Education and Science 1988: 29).

The complementary aspect of the enlarged institutional autonomy is the system of quality control. As stated in all recent governmental documents on this topic: 'the 
abolition of regulations with which institutions must comply in advance, goes hand in hand with stringent output control'. It is left to the institutions themselves to develop a system which will generate both quantitative and qualitative information. However, if institutional efforts in this are below standard, the government retains the option to take over the monitoring of standards through an independent higher education inspectorate, which at the moment is already constituted. ${ }^{1}$

The third basic change in governmental policy-making presented in the HOAKdocument, is the introduction of a new system of planning and funding. In 1987 the draft Higher Education and Research Plan (HOOP) was published, a five-volume document circulated for consultation and comment, including analyses of the higher education system, policy proposals, facts and figures and financial schemes. The final version was published in February 1988. The HOOP is an essential ingredient in the newly proposed two-year planning cycle. In the first year of the cycle, the government produces the HOOP, in which problems and issues are set out which the minister believes require particular attention in the planning period. This 'agenda' is then discussed with the institutions. In the second year, the institutions produce their development plans, stating how they will address the issues raised and what their future course of action will be. The next HOOP in turn will address these plans and relate them to the present problems and issues, resulting in a new agenda, etc. The system is constructed in the form of a dialogue between government and institutions, designed to increase their involvement in the community.

One of the central issues which has been raised in the first HOOP is the construction of institutional profiles and the formulation of institutional missions. Institutions are expected to develop long-term strategic plans stating their views and positions on both demand and supply of teaching, and research priorities. An institutional profile should distinguish an institution from others, while at the same time serve to strengthen the separate identities of the university and the HBOsubsystems as a whole. In the HOOP, emphasis is placed on institutional outputs, among others, translated in proposals for the present funding, including the introduction of a student voucher system and a so-called 'mission budget', to further underline the quasi-market approach to which government has turned and which the institutions are expected to follow.

The concept of a mission budget has been introduced on the grounds that the minister retains his own responsibilities for guaranteeing pluriformity and variety of the system within the framework of institutional self-regulation. In those instances where required developments originate too slowly or insufficiently, the minister can exercise his political responsibility by allocating a mission budget. It can be seen as an incentive for institutions to adequately react and adapt to environmental developments.

If the HOOP can be seen as an administrative translation of the philosophy presented in the HOAK-document, the WHW-bill can be seen as its legislative translation. It formalizes the replacement of central government regulation with the decentralization of powers to the higher education institutions. At the time of writing, the bill is under discussion in parliament. However, in the period between the publication of the draft-bill and the parliamentary discussion, some important 
events occurred. First of all, because of strong dissent within both the higher education community and the political parties, the idea of a voucher system has been dropped for the time being. Second, and most important, a new government came to power, which resulted in a change of Minister for Education and Science. The christian-democrat Deetman was replaced by the labour party candidate Ritzen, previously professor of economics at the Erasmus University of Rotterdam. Even though Ritzen indicated that in general he would follow the overall policy direction set out by Deetman in terms of 'government at arm's length', he amended the WHW-bill on some fundamental points (Government Amendment, 21 073, no. 5).

First of all, the 'sector' is taken out of the bill and replaced by a 'Central Register of Higher Education Courses': a database containing information on courses and subject areas, and the outcomes of the quality assessment processes discussed above. Only those courses which are registered will be funded by the government and will be able to award certified degrees. Also, students will be eligible for student support (grants and loans) only if enrolled for registered courses. If the quality assessments result in negative judgements for a number of years (not further specified) the course will be dropped from the register, implying no government funding, student support, or certified diplomas.

Second, the institutional registration fee is no longer fixed; institutions can vary the amount, however, the maximum is set by the government.

Third, the right for institutions to determine the yearly entrance numbers will be incorporated in the Act, on the condition that these numbers will not be less than $70 \%$ of the average inflow during the last three years. If student demand exceeds available places, institutional capacity for those areas should be expanded to at least $125 \%$ of the average capacity over the last two years.

Fourth, the concept of the 'mission budget' is taken out of the Act.

Fifth, possibilities for institutional co-operation between $\mathrm{HBO}$ and universities are enlarged. However, separate programmes and degrees, in terms of the binary distinction, should remain visible.

Sixth, ex ante approval of the institutional budget is no longer required, nor are development plans. Control will be based on the yearly institutional accounts, which should also incorporate a section containing the institutional plans regarding future developments. The abolition of the development plan as an institutional document basically removes the rationale for the HOOP cycle discussed above.

The arguments for these rather drastic changes in the WHW-bill are first, that the concept of the 'sector' would not really be workable. Not only did it prohibit flexible institutional adaptation to changing needs in society, because an institution was confined in its 'adaptive responses' to the allocated sectors, but also the sector system insufficiently clarified the educational programmes available. Programmes with the same name, could be completely different at different institutions, and programmes with different names, because of different sectors, could basically be very similar. The 'register' system, according to the minister, would inform more adequately on the similarity and diversity of higher education programmes. Be this as it may, it also means a substantial change in the steering level of higher education 
policy. The original idea of the introduction of the sector level was that through this construct governmental steering would no longer be directed at the programme level, because this did not correspond with the overall philosophy of 'government at arm's length'. The proposed change again redirects governmental steering at the programme level, especially because of the connection between quality assessment and governmental funding.

Regarding the 'liberation' of the registration fee, the argument is that institutions will be able to offer a favourable price/quality ratio to students, with the database providing the possibility for students to check this ratio. In this way 'some room for competition between institutions is created, enlarging the dynamics and diversity in higher education' (Government Amendment, 21 073, no. 5). An essential element in this is the suggested 'purity' of the information available through the assessment procedures. We will return to this below, arguing that one can have severe doubts about the viability of such a system. However, it should be emphasized that these amendments are proposals and not established government policy. Already parliament has expressed its doubts about the viability of the amendments. It remains to be seen to what extent, if at all, they will be incorporated in the final Act. This will also shed some more light on the political relationship between the minister and parliament (see further).

With respect to the relationship between universities and HBO-institutions, it is hard to imagine what institutional co-operation in terms of programmes should occur if the binary divide is to remain explicitly visible, especially since new forms of education between university and HBO education are certainly not intended. Regarding the binary nature of the Dutch higher education system, it seems appropriate to focus on the developments that have led to the structure of the HBO-sector as we now know it, since this very likely will have some profound effects on the future structure of the Dutch system.

Although the distinction in two types of policies, the 'corrective' and 'option supplying' ones, fits the purpose of a classificatory scheme, it is not fool-proof. One important government-induced restructuring operation rests somewhat uneasily in this dichotomy, namely, the merger operation which fundamentally changed the structure and role of the non-university (HBO) sector of higher education (Goedegebuure 1989). The operation, entitled Scale-enlargement, Task-reallocation and Concentration (STC), was started in 1983 with the basic objective of strengthening the HBO-institutions both in a managerial and an educational sense so as to become a full part of the higher education system - equal but different in relation to the universities. Or, to use a different phrase, the objective was to 'upgrade' the HBO-institutions (Teichler 1988). In this respect, STC was the eventual implementation of discussions and ideas on the structure and position of the non-university sector, dating back to the mid-1970s. Before the STC-operation, the HBO-sector consisted of approximately 350 small, mono-purpose institutions of which two-thirds had an enrolment level of less than 600 students. By 1987 the number of institutions dropped to some 85 , out of which 51 were large to very large, mostly multi-purpose institutions. At present mergers still continue within the $\mathrm{HBO}-$ sector. The end result of this wholesale restructuring has been that $\mathrm{HBO}$ has 
become a potentially powerful force next to the universities in the Dutch higher education system. However, it has also meant that the sector has been in turmoil for some five years, and is still settling down from the not always easy and supple organizational and structural change process. This to a large extent accounts for the fact that, for example, the developments regarding a system of quality assessment appear to lag behind those in the university sector. However, the results of the merger operation also show the potential strength of a government operating at arm's length. Contrary to the retrenchment operations of the early half of the $1980 \mathrm{~s}$ in which the government's role was dominant and penetrating, the STC-operation was structured in such a way that only a limited number of boundary conditions was specified by the government, no fixed goals in terms of number of mergers or institutions were stated, and the actual process was left to the institutions and the HBO-Council themselves. In effect, the policy adopted strongly resembles the basic concepts that were to be incorporated in the new steering philosophy described above.

\section{Towards a framework for analyzing policy change}

As has been described above, Dutch higher education has undergone a number of more or less far-reaching reforms and retrenchment operations, the outcomes of which only partially correlate with the stated objectives. On the one hand, this can be seen as underpinning Clark's often quoted statement that higher education changes only gradually and incrementally (Clark 1983: 182). On the other hand, it also can be seen as an indicator of the opposite, that is to say that it is remarkable in the light of the often stated barriers to change in higher education (see, e.g., Becher and Kogan 1980; Cerych and Sabatier 1986; Van Vught 1989) that Dutch higher education has changed as much as it has. Whatever position one prefers to take, it is beyond doubt that, through the various interactions between the key actors in the system, a certain amount of change has occurred, as well as that the dynamics of interaction have resulted in both intended and unintended outcomes of these change processes.

Below we attempt to formulate an analytical framework that can be used for empirically assessing the change processes confronting Dutch higher education - a framework that might also have some wider use in analyzing policy change and its outcomes in higher education in general, as it is based on a number of general notions and assumptions drawn from the social sciences. Since these theoretical statements relate to the interactions that occur between the various actors who operate within the higher education system, as a first step in formulating the framework an analysis of the system in terms of relations and interactions is called for. In this, the higher education system will be approached as an interorganizational network. In this approach we will also formulate some propositions about the behaviour of the key actors or organizations within this specific network. 


\section{The Dutch higher education system: an inter-organizational network}

The Dutch higher education system and the policies relating to it can be considered to be the resultant of the behaviour of a number of organizations that can all be viewed as more or less public, governmental organizations. On the one hand, this means that the individuals and organizations in the field of higher education behave in principle like all other individuals or organizations: they strive for maximization of their own utility (De Alessi 1983; Lieshout 1984; Moe 1984; Westerheijden 1988). As Clark points out: 'He who says academic organization says interest groups' (1983: 10). On the other hand, the context of these individuals and organizations has some consequences for the way these principles will be transformed into observable behaviour. Most important here is the fact that the organizations together form an inter-organizational network of (mainly) governmental organizations (see Figure 2).

The system itself, from an analytical point of view, can be divided into a number of separate relationships which are related to the different positions occupied by the actors. A well-known structuring of these relations is the distinction made by Clark 205-206) in understructure, middle structure and superstructure. Worthwhile as this analytical concept is, both for our purposes and for the reality of the Dutch system, we propose a slightly more detailed distinction, based on the functional relationships that exist in the system. We discern the following:

1. the political relationship between the minister and parliament;

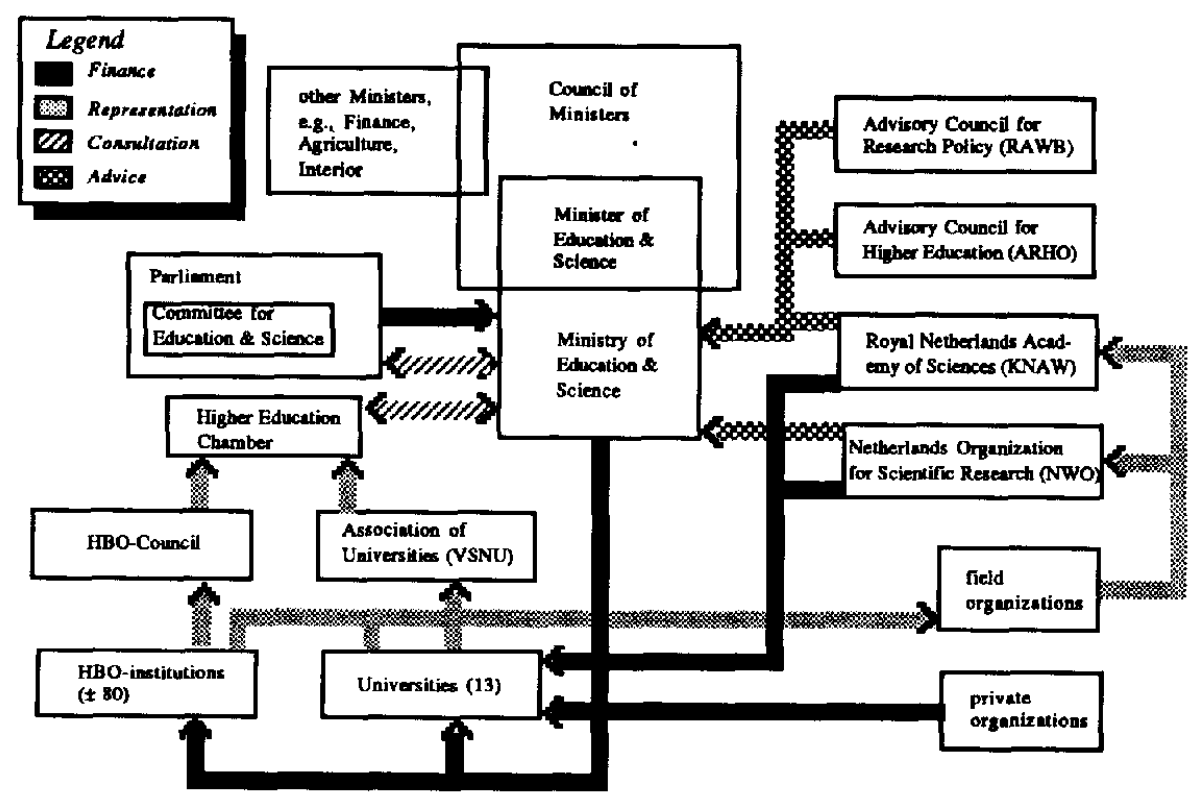

Fig. 2. Actors and relations in Dutch higher education. 
2. the administrative relationship between the minister and the higher education institutions;

3. the inter-institutional relationships; and

4. the intra-institutional relationships.

Within these relationships a number of essential dependencies exists, which, as we will argue later, to a large extent influences the outcomes of government-initiated reforms or changes in the system.

\section{The political relationship between the minister and parliament}

Among the governmental organizations in the field of higher education, the Ministry of Education and Science is by far the largest. It occupies itself mostly with the educational and research institutions, and for that reason alone it would make a good candidate to be called a central actor. The 'power of the purse' it wields $v i s-\grave{a}$-vis the higher education institutions is another reason, as is the relationship between the Ministry and parliament. The Ministry of Education and Science provides parliament with almost all of parliament's proposals relating to education and sciences, both for budgets and for policies. Yet parliament is far from powerless in its relationship with the Ministry, for without parliamentary consent a ministry would not be able to spend a single guilder or make a single regulation. As long as processes in the relationship do not escalate much above the normal level of intensity, however, most decisions are made within the Ministry, while parliament exerts only marginal influence. ${ }^{2}$ In the daily routine of decision-making, parliament cannot control and sanction all of a ministry's actions. This gives the Ministry leeway to take action without explicit parliamentary consent: as long as no dissent is heard, parliament is supposed to give its consent. Only when the Ministry has to deliberate with parliament by rule (as when a draft of law is to become a law), and in case conflicts arise between parliament and the Ministry (represented by its minister), the odds are in favour of parliament, because it can force a minister to resign. The power relationships between a minister and parliament are, therefore, complicated: as long as consultation of parliament is not required, a minister (and the Ministry) may be reckoned to occupy the most powerful position, but as soon as debates start in the plenary session of parliament, the relationship is reversed and parliament is more powerful than the minister.

The administrative relationship between the minister and the higher education institutions

The raison d'être for the higher education system is education and research. The universities and the HBO-institutions can be considered to be the central organizations in the system. For their (financial) means of existence they are primarily dependent on the political institutions, viz., parliament, minister, and the 
Ministry of Education and Science. From the perspective of the universities and the HBO-institutions, their relations with the political institutions are the most important, simply because these institutions decide upon the budgets; budgets set the 'limits of behaviour' for universities and HBO just as much as for any other organization: ' $\ldots$ the range of services any agency can provide is determined ultimately by the money it is authorized to spend. Money talks, in administration as elsewhere' (Rourke 1969:25). The relationships with other organizations are in this respect much less important for the higher education institutions. Almost all the financial resources are provided by the Ministry, while the subsidies by the Netherlands' Organization for Scientific Research (NWO) or contracts with social or commercial organizations (primarily business firms) account for only a small part of the income. Moreover, the political institutions are also important as regards the legitimation of universities and HBO in society (especially with respect to the societal effects of diplomas), although the (national and international) 'field' of the discipline, and sometimes social and commercial organizations, can play a part in this respect too. It is not to be expected that the policies of universities can differ systematically, in the long run, from the preferences of policy-makers in the Ministry, provided these policy-makers have preferences regarding higher education and are able to use the (financial) relationships to further their preferences. It is this relation that makes the sector of higher education a 'semi-feudal conglomerate' of organizations (Allison 1971), in which, from the point of view of power relations, the position of the Ministry of Education and Science is higher than that of each of the institutions of higher education.

However, this is only a partial view; the institutions themselves are certainly not completely powerless, bending to whatever is thrust upon them by the minister or his governmental officials. Not only do institutions possess power through their informal relations with parliament, ${ }^{3}$ but also they are by definition the dominant providers of the educational and research goods the government obtains on behalf of society at large - goods that are highly important and cannot be substituted very easily with something else. This makes the government with respect to the 'product', higher education, highly dependent on the institutions. In combination with the already noted high dependency of institutions on the government in terms of resources, the relationship between the minister and the institutions is therefore best described in terms of mutual dependencies, as is indicated by Figure 3 (Scharpf 1978: 355-356).

It should be noted at this point that, as can be concluded from both exchange theory (Blau 1964; Levine and White 1961) and the resource dependence perspective (Aldrich 1979; Benson 1975; Pfeffer and Salancik 1978), the existence of mutual dependence relationships does imply that governmental policies also have to be geared towards the preferences of the higher education institutions if they are to be effective in the long run. From this it can be hypothesized that the more governmental policies directed at change are in accord with existing preferences of the higher education institutions, the more likely it is that these policies will be successful in attaining the government's objectives (see also Van Vught 1989). This may be a trite proposition, but we shall elaborate on it below. Moreover, it is understood that this 


\begin{tabular}{|c|c|c|}
\hline \multirow{2}{*}{$\begin{array}{l}\text { substitut- } \\
\text { ability of } \\
\text { the resource } \\
\text { high }\end{array}$} & \multicolumn{2}{|c|}{$\begin{array}{l}\text { importance of the } \\
\text { resource }\end{array}$} \\
\hline & $\begin{array}{l}\text { high } \\
\text { dependence }\end{array}$ & $\begin{array}{l}\text { low } \\
\text { dependence }\end{array}$ \\
\hline low & $\begin{array}{l}\text { low } \\
\text { dependence }\end{array}$ & $\begin{array}{l}\text { indepen- } \\
\text { dence }\end{array}$ \\
\hline
\end{tabular}

\begin{tabular}{|c|c|c|}
\hline \multirow{2}{*}{$\begin{array}{l}\text { B's } \\
\text { depend- } \\
\text { ence on A }\end{array}$} & \multicolumn{2}{|c|}{ A's dependence on B } \\
\hline & high & low \\
\hline high & $\begin{array}{l}\text { mutual } \\
\text { dependence }\end{array}$ & $\begin{array}{l}\text { unilateral } \\
\text { dependence }\end{array}$ \\
\hline low & $\begin{array}{l}\text { unilateral } \\
\text { dependence }\end{array}$ & $\begin{array}{l}\text { mutual } \\
\text { independence }\end{array}$ \\
\hline
\end{tabular}

Fig. 3. Types of dependencies.

proposition is made ceteris paribus: it only applies to the relationship between the government and the higher education institutions, and there may be many other reasons why policies are not successful.

Mutual dependence does not imply equality of both actors' power positions. While in a formal sense, the power of a ministry is quite extensive (it has discretionary powers, legitimately built into a wide array of policy regulations, which provide ample possibilities to apply or alleviate all degrees of pressure), it lacks one essential ingredient in its array of powers, namely, information. Because of the specialized nature of the field of higher education, a ministry will never have enough useful information to fully steer the system in the desired direction. Through their almost monopolistic control of information, the institutions possess a strong source of power vis-à-vis the Ministry; a source which enables them, in those instances in which policy change is perceived to be a threat to the status quo, to act in accordance with the ministerial change on the surface, but in effect act in a way which 'corrupts' the policy change from within. On-the-surface compliance is then combined with actual obstruction, the end result of which will be a situation that differs from the status quo, but that still to a large extent accords with the existing preferences of the higher education institutions. Or, as an elaboration of our first hypothesis, the more governmental policies directed at change differ from existing preferences within the higher education system, the more likely it is that these policies will only result in a limited amount of change through defensive institutional behaviour. Dutch higher education policy during the last decade provides a number of examples that appears to support both these hypotheses. With respect to the latter one, the developments in the field of quality control are indicative, while with respect to the first, the restructuring of the $\mathrm{HBO}$-sector appears supportive.

\section{Quality assessment}

An example of the way in which institutions on the surface can act in accordance with a governmental policy aimed at change in the system, while at the same time working their way around it, is the implementation of the system of Conditional Funding (CF) of research. The system, introduced to increase accountability, quality, and institutional research policy, is based on two pillars, namely external 
quality assessments and budget reallocations. On the basis of the outcomes of the assessments, reallocations according to whether research was judged as 'bad', 'good', or 'excellent' were envisaged. Based on the results of their evaluation study of the CF-system, Spaapen et al. (1988: 110) conclude that:

... in the eyes of the institutions, [the] two most dangerous components of the CF-system, external assessment and reallocation, are being stripped of their thorns during the introduction process. Regarding the external assessment, this is done by delegation and encasement; the ad hoc and the international element disappear; the organisation is placed in the hands of the VSNU, and the implementation in the hands of some important, with the universities related, bodies. Decisions on reallocation are put on a back burner.

Taking this theme a bit further, Bijleveld and Goedegebuure (1989) show that in the face of governmental attempts to reinstall the dynamic interplay between assessment and reallocation, institutions managed to keep close to the status quo. Their proposals for reallocation effectively implied hardly any reallocation, while the assessment procedures remained a 'black box' to the government, with the assessing bodies not willing to make distinctions between good and excellent research. Bijleveld and Goedegebuure tentatively conclude that the universities have successfully fought the attempt of government to enlarge its grip on the scientific research system through the introduction of the CF-system. At present the system is under revision.

Regarding the assessment of quality of teaching, a somewhat different picture emerges. In this area, more progress appears to have been made with the functioning of a system primarily directed at quality improvement (Vroeijenstijn and Acherman 1990). Westerheijden poses that the dilemma regarding quality assessment is that 'without the expectation of real consequences, the incentives to organise quality assessment are lacking; with the expectation of real consequences, quality assessment will turn into a power game' (Westerheijden 1990a: 205-206). The universities seem to have found a way around this dilemma, in that they try to reduce the consequences to educational consequences (improvement of courses), rather than financial consequences (reallocation or retrenchment). It is, however, too early to make positive statements about the universities' success to evade the dilemma, as the assessment system of teaching quality is only beginning to operate (Westerheijden 1990b: 22). Besides, an uncertain factor at the moment is the extent to which teaching-quality assessments will be linked with governmental policy (implying a direct financial relationship) by way of the quality registration envisaged in the WHW-bill.

What these examples show with respect to university behaviour agrees with the hypotheses stated above. The universities have a strong power-base in their control over information in their relationship with the government, and they use it if policies directed at change threaten the status quo. If no direct threat is implied, university behaviour is more in line with policy objectives. 
Through the STC-operation described above, the HBO-sector has been drastically restructured. Based on their evaluation study of the STC-operation, Goedegebuure and $\operatorname{Vos}(1988)$ conclude that attitudes towards the operation were positive from the start and became more so during the operation itself. An explanation for this can be found in the overall perspective underlying the restructuring operation. The basic aim has always been to upgrade the HBO-sector to an 'equal but different' counterpart of the university sector, to take it out of the legal confinements of the secondary education sector, and to restructure funding and management procedures. In this sense, the government, through its policy, heeded the calls for more autonomy, recognition of a higher education status, and changes in funding from within the HBO-sector. This coincidence of policy direction and existing preferences has led Teichler to the observation that in effect the STC-operation could be seen as a non-controversial reform (Teichler 1986), and it can explain to a large extent why the ideas of the restructuring policy took hold in the HBO-sector in the first place, thereby supporting the hypothesis formulated above. It does not explain, however, why the STC-policy has been adopted to such a large extent. In general, merger - the predominant instrument in the restructuring policies - is something an organization tends to avoid as much as possible, since it involves a loss of autonomy and alters existing power structures (e.g., Meek 1988; Millet 1976). In this sense, the results of the restructuring operation appear to contradict the second hypothesis formulated above, also implying that a framework restricted solely to the relationship between the government and the higher education institutions is too narrow to adequately address the issue of policy change in higher education. For a more complete framework, the inter- and intra-institutional relationships should also be included.

\section{Inter-institutional relationships in the higher education system}

As we have argued above, the restructuring operation in the HBO-sector in its policy-design strongly resembled the 'remote control' concept that was introduced by the Dutch government in its HOAK and subsequent policy documents. In these, emphasis is placed on the introduction of 'market' notions in the system through competition, a focus on quality, performance, etc. It should be noted here that when the concept 'market' is used in Dutch higher education, we are dealing with a very specific type of market. There is a relatively small group of 'producers', the universities and HBO-institutions, and only one dominant 'buyer', the government, who is, with the exception of teacher training, not the consumer of the 'products', education and research. In this sense, no direct market relationship exists in the strict economic meaning. Students consume education, but are only marginally paying the costs for this, and society at large is using the 'benefits' of scientific research, but is only indirectly paying for it through taxes. ${ }^{4}$ The policy changes described earlier as 'option supplying' do not alter this. Students are not going to pay directly, e.g., through a voucher system, for their education, and research 
money is still being allocated by government, albeit through an intermediate body (NWO) which is not a direct consumer either. In this respect no basic changes in 'market relationships' are carried through. What is happening, is that more competition is introduced in the inter-institutional relationships. Although we are treading on slippery ground here, since most of the changes are either still on paper or have only just been implemented, we will try to make some assessment of possible effects and consequences. These assessments are based on the theoretical notions regarding institutional behaviour introduced earlier.

The main argument used by the government to support its change in overall policy direction is that, through releasing its former strong regulative grip on the system, introducing more competition, and intensifying 'output steering' primarily based on quality notions, the system itself will become more adaptive to changing environmental demands resulting in diversity and an increase in the 'overall quality' of the higher education system. A number of forces is at play at the interinstitutional level that might either promote or deflect diversity and an increase in quality.

It has been shown that in general the overall change in policy direction by the government is supported in the higher education field (Binsbergen and De Boer 1988). However, we also have to deal with inter-institutional dynamics. In this, strategic behaviour is likely to play a prominent role. Earlier, we argued that the outcomes of the STC-operation were in fact far more pronounced in terms of scale-enlargement than might be assumed if one takes into account the uncertainty and loss in autonomy which go with mergers. Elsewhere, Goedegebuure (1989) has argued that this can be accounted for in terms of strategic behaviour displayed by the HBO-institutions. Within the framework of HOAK and the HOOP planning documents, an institution's chances for survival are highest if it comprises all the 'sectors' created by the government. Not only would this ensure the widest possible range of courses that an institution could offer, but also the greatest chance of attracting students. ${ }^{5}$ The government also made it clear that additional funding mostly in the form of project grants - would be allocated to those institutions that offered a broad study profile, i.e., large, multi-sectoral institutions. The mergers that were realized towards the end of the STC-process - when the HOAK-philosophy began to take firm ground - confirm this strategic behaviour. The mergers that occurred after the formal end of STC without exception can be explained from this point of view. At the moment, around $70 \%$ of all students in non-university higher education are enrolled within the 24 (28\%) largest institutions. If the assumption holds that merger behaviour is geared towards ensuring a future competitive edge, or at least creating a power position as strong as possible in terms of course-offerings in relation to other institutions, it can be reasonably expected that a new round of mergers will occur in the near future (possibly bringing the number of institutions down to some 25) if the government proposals regarding the changes in the WHW-bill are supported by parliament. Above we described how the 'sectorconcept' was dropped and how it will be replaced by a register. This means that every institution can offer all the courses it wants; courses it thinks will be profitable in terms of student attraction, etc. At present, available sectors within institutions 
place a barrier to this, and 'protect' (intended or not) quite a number of small(er) institutions in the geographical neighbourhood of large, multi-sectoral institutions. Since these larger institutions at present do not 'possess' all sectors, the smaller ones are in no direct danger from their big brothers, as these cannot trespass on their educational turf. If this barrier is removed, it is highly likely, for the reasons discussed above, that the large institutions will enter these fields of study (e.g., higher economic and administrative education), making life for the small ones extremely difficult. Merger is then one of the most likely available options for these small institutions to at least partly ensure their survival. If they do not merge, the chances are that they will be 'driven out of the market', to use an economic phrase. Only those few very specialized small institutions with high (international) reputations and strong selection policies because they are in high demand, e.g., hotel management in The Hague, and industrial design in Eindhoven, appear to be in a position to guard their niche. For the others, an independent future looks ominous if policies are to be implemented as they are presented now, and if our assumption about strategic behaviour is correct. If the policies are implemented, this can be easily tested. Another consequence of this - and certainly unintended from the government's point of view - is that it is questionable whether these developments will result in the envisaged diversity, since what could happen is that institutions will be 'crowded out' of the market through duplication of their course-offerings. In terms of diversity this is a zero-sum game.

The effects of changes in the government's higher education policy with respect to diversity are, however, not only limited to the HBO-sector. Two points are worth noting here, with respect to diversity within both the university and $\mathrm{HBO}$-sector, and between universities and $\mathrm{HBO}$-institutions. First, it remains to be seen whether the 'within' diversity of course-offerings will develop in the inter-institutional competitive setting envisaged by the government's policy. Research in the United States, often used as proof to the statement that a 'market-like' system increases diversity, can equally be used to prove the opposite. Birnbaum (1983: 68), in reviewing the literature on this topic (Anderson 1977; Baldridge et al. 1978; Hodgkinson 1971; Martin 1969), states that:

The work of the critical analysts and the empirical researchers can be cited to support claims that diversity in higher education is decreasing, is increasing, or has remained constant. Scholarship of the early 1970 s and before tends to endorse findings suggesting diminished diversity; more recent works are more optimistic.

In his own contribution, Birnbaum uses the natural selection model in which institutional diversity in higher education is directly related to the environment. $\mathrm{He}$ concludes that for American higher education a scenario in which diversity will have decreased by the year 2000 , in which there will be fewer institutional types, and institutions will look more and more alike, is more probable than a scenario in which diversity will be maintained. According to Birnbaum, the environment will become more uniform, and institutional diversity is likely to be reduced as a result (1983: 144-145, xii). A somewhat similar stance, though on a more general level, is 
taken by DiMaggio and Powell (1983; for a discussion of their approach, see the article by Meek). This, of course, poses the fundamental research question of whether the policy changes recently introduced or about to be introduced in the Dutch system will indeed lead to an increase in diversity. On the one hand, one can argue that in a more 'free' context, institutions will search for niches through specialization and profiles, according to the basic thesis of the market-philosophy, thus increasing diversity. On the other hand, one can argue that, in order to reduce the uncertainty confronting them, institutions will copy the behaviour of successful competitors, thus generating a system in which the various organizations become more similar instead of more diverse. In terms of risk-aversion and investmentcosts, the latter option certainly is the cheapest. A clear example of this can again be found in the HBO-sector following the STC-operation. Confronted with their newly found freedom the institutions did not engage in a variety of new, innovative activities, but, according to the intentions stated in the 1989 development plans, to a very large extent all opted for internationalization, extension of contract research and teaching (the 'entrepreneurial approach'), etc. ${ }^{6}$ In other words, they all emphasized those areas which, at that time, were highlighted as the key areas an institution had to engage in if it were to be an institution that counted: developments which certainly do not support the assumption that through deregulation institutions will opt for differentiating behaviour.

Second, what goes for institutional behaviour within the same 'league' also goes for the behaviour between the two leagues. It has been observed that binary systems by their nature are basically unstable, and often contain the seeds of their own destruction (Meek and Goedegebuure 1989). Certainly, Australia is an example of this. With respect to the Dutch situation, both elements of 'upward' and 'downward' academic drift can be observed. Regarding the upward academic drift, HBO-institutions, and their intermediate body the HBO-Council, are at present putting pressure on the minister to include research as a legitimate task for them in the WHW-bill, thereby going exactly the same way as both colleges of advanced education in Australia and polytechnics in Britain have gone. Or, in terms of Neave (1983), they display the dynamics towards integration in the 'noble' sector. The recent proposals by the minister to separate teaching from research funding, and to allocate research budgets on the basis of a competitive system in which the quality of the proposal plays an essential part, could be an interesting case. The binary divide is to remain, in the view of the minister, but what happens if HBO-institutions join in the competitive process? Can NWO (the organization that is to allocate a large part of the research budget) exclude $\mathrm{HBO}$-applicants simply because of their binary position? If the system is to be based on the quality of the research to be undertaken, this seems hardly a viable option, and could certainly be questioned under the equal rights regulations operating in the Netherlands. Certainly, in the fields of humanities or social sciences, where no extensive infrastructure is necessary, this is not a far-fetched conjuncture, especially if we note that the boundaries between applied and fundamental research in these fields are highly blurred in the university system. The basic question in this is of course whether HBO-institutions will decide that their strength and legitimate role can be found in their relationship with the original 
reference groups, thus stressing the vocational element of the curriculum, or whether they will opt for the struggle with the major league as has happened in other countries. This 'choice', if we can call it that, cannot be seen in isolation from the downward academic drift that can be observed in the Netherlands. As in many other countries, Dutch universities engage in traditional vocational education with respect to medicine and dentistry, which by definition have little to do with academia. However, more recently, universities have also engaged in all sorts of applied sciences like journalism, nursing, leisure studies, etc., which seem to fit rather awkwardly with the strict binary divide the minister has in mind. But, these are areas for which a market demand exists. Such developments are, of course, a thorn in the eye of HBO. Again, one can wonder whether a system in which every institution is free to develop courses with the only restriction being a sufficient quality will result in increased diversity or copying behaviour. If prestige remains tightly tied to research achievements, and if that is the area in which resources can be obtained, upward academic drift remains a viable option in the Dutch situation. If binary divisions remain blurred in terms of educational provision, and there appears to be no solid argument in a more market-driven system that this will not be the case, then diversity will not increase either.

Our proposition regarding the inter-institutional relationships referred to above relates to the following. Since the changes in Dutch higher education policy do not really alter the existing dependencies between the government and the higher education institutions, but enhance the competition between institutions, institutions are more likely to engage in copying behaviour. Thus, they are more likely to become similar rather than different, because through this behavioural attitude, based on survival, resource dependence, resource maximization, and strategy, they are more likely to assure survival and a sufficient amount of resources than if they engage in differentiating behaviour.

This, however, does not imply that there is some sort of 'iron law' through which the end result will be a completely homogeneous group of higher education institutions in a stable state. First of all, for institutions to engage in copying behaviour, there has to be something to copy, that is, some institutions at stage $n$ will be 'better', more innovative, or whatever label one wants to use to indicate a difference between institutions. If other institutions decide to copy this, it by definition implies that those institutions from which something is to be copied, are successful, thus generating extra resources, be it money, prestige, etc. If, then, at stage $n+1$, the other institutions have copied the successful elements, the original, first (group of) institutions will still be better placed in terms of resources, thereby being better placed to create the organizational 'slack' from which to develop a new competitive edge. This line of reasoning starts from the assumption that higher education institutions are not equal, that hierarchies exist, and that these to a large extent determine the possibilities of evolutionary growth. Green (1980: 77), borrowing the term from Riesman, describes this as the 'reptilian procession':

Certain institutions will initiate reform .... Other institutions, seeing what has been done, will follow in the same path, reaching implementation usually about the time that the original innovator has set off in 
a new direction. Those institutions at the head of the procession, however, are not there by chance. They are first usually because they occupy a position of high status in a system of educational stratification.

Certainly, in Dutch higher education, hierarchies do exist; there are reputational differences between universities, as well as between HBO-institutions. For example, the HBO-Council first discusses policy initiatives with the so-called 'group of eleven' (the eleven largest institutions) before discussing them with the others. And in the university sector, the older universities by and large occupy the more esteemed positions. The interesting point in this of course is that, although most of the time it is presented the other way round, these institutions did not obtain their reputation by being just old(er), but because of the fact that throughout the years (or centuries) they have been able to attract high-class scholars to work in their institutions. In a way, this is but a variant on the 'Matthew effect' (the richer get richer), but nevertheless it appears to be true. In this sense it would be an oversimplification to view higher education institutions as united, unitary actors, since by nature there exists a special relationship between the academic staff member and the institution. We will elaborate on this by addressing the fourth type of relationship: the intrainstitutional relationship.

\section{The intra-institutional relationship}

The system of higher education and research displays some peculiarities as a consequence of 'the special nature of knowledge'. In short, the organization of

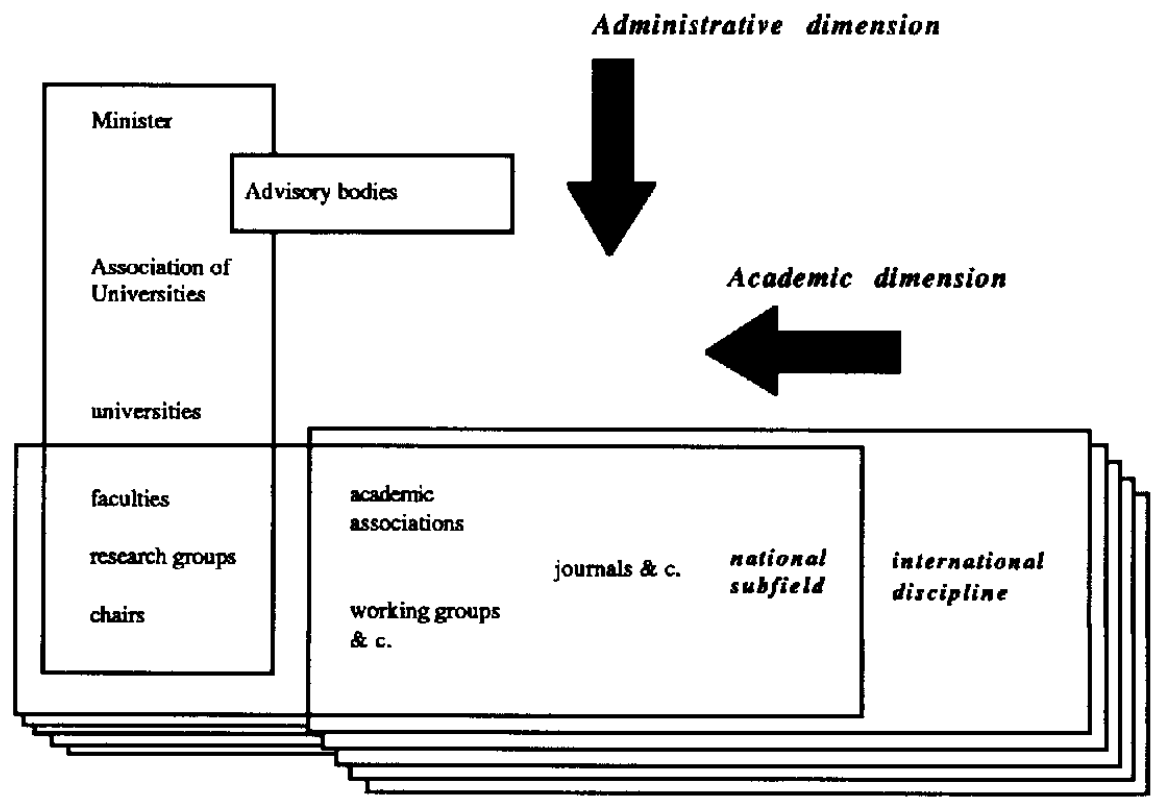

Fig. 4. The matrix of higher education. 
'knowledge' is like a large matrix structure, organized along the dimensions of scientific disciplines on the one hand and educational and research institutions and government organizations on the other (see Figure 4). We could call these the academic and the administrative dimensions, respectively.

The matrix structure has consequences on the level of the individual university. First, the matrix structure more or less repeats itself in the twofold structure of universities; on the one hand the 'bureaucratic' organization of the institution, on the other hand the structure of the academic, disciplinary field. The academic side of universities is, according to Clark (1983: 17): '[a] flat structure of loosely coupled parts . . . a federation, or perhaps even a coalition, rather than a . . bureaucracy'. Even though in the 'theory of political behaviour' all organizations are coalitions (since each individual participates with a view to his/her personal utility), the special character of academic organization must be noted; as Clark, Whitley and others have remarked, it resembles a 'craft' or 'guild' structure more than a bureaucratic structure (Clark 1983: 113; Kogan 1984: 62; Whitley 1984: 14-15). Which means, in this case, that legitimate power relations are discipline-rooted rather than institution-based. Like the workshops of medieval guild-masters, the primary operating unit is the chair or the basic unit. ${ }^{7}$ In such operating units hierarchical relationships do exist, but they only comprise a few layers. Between operating units relationships are mostly horizontal, primarily with other units of the same discipline. The units of a discipline together form a major part of the "national subfield': the community of scientists in a discipline, who together exert power over its members and deal out reputations, e.g., by means of peer review (Whitley 1984). This control over its employees from outside the institution, with its emphasis on expertise and academic freedom, makes the situation of the administrative side of the university rather awkward: it can neither control the primary processes of teaching and research in detail, nor has it exclusive rights and possibilities for this task. Rather, it has to share the influence on the primary processes with the national subfield. All this makes the chair or the basic unit not only the focal point in a university, but also 'unusually strong and central' (Clark 1983: 31-32) in decisionmaking processes. Second, the matrix structure divides the academic side of a university, in its turn, along disciplinary lines. It is rightly suggested that: ' $[t]$ he core membership unit in academic systems is discipline-centered', because: '[i]t is more costly to leave one's field of expertise than to leave one's university or college ...' (Clark 1983: 33, 30). Therefore, the disciplinary lines in universities are real cleavages.

In the context of the changes confronting the Dutch higher education system, the intra-institutional relationships raise some problems. To a large extent government policy focuses on the institutional level, i.e., the institution as a whole. Institutions are supposed to develop profiles, engage in innovative and differentiating behaviour, etc. However, the most important element incorporated in the new approach, the introduction of a quality register and the interconnecting of funding with quality assessment outcomes, is directed at the study programme level. This leads to a fundamental imbalance in the policy approach. As we have indicated earlier, the institutional administrative elite to a large extent is in favour of the 
proposed changes embedded in the HOAK-philosophy - an attitude that relates very well with notions of self-interest and power positions, since it furthers the role of the administrator in the institution (see also Meek and Goedegebuure 1989). Nevertheless, the HOAK-policy hardly changes the existing dependencies between administration and academics. ${ }^{8}$ Funding is still tied to the academic side of the institution, and, as we have argued above, academic interest lies with the discipline and not with the institution. The favourable attitudes of administrators to the change process set in motion can certainly not be assumed to pertain to the academic part of the institution. This is not altered by the fact that funds are allocated as a lump-sum to the institution and are reallocated by the administrative (central) level to the faculties. It is impossible to predict what effects this imbalance contained in the government approach will have on the higher education enterprise. One can imagine an intensified struggle between the central administration on the one hand, trying through the implementation of (strategic) development plans, mission statements, and the ensuing managerial tools to move the institution to new avenues in the changing higher education market, thereby emphasizing the notion of the higher education enterprise, and the academic side of the institution on the other hand, being not really interested in the fashion-of-the-day, but in furthering its own position in the academic system by performing those activities that bring them respect and recognition of their peers. It cannot beforehand be assumed that these activities will correlate fully with those envisaged by the institutional management. In this respect the intra-institutional division of power and the possible changes therein, because of the overall policy change in Dutch higher education, will be an interesting and fruitful area of research in the empirical stage of the comparative project. That the concept of power is difficult to deal with in empirical research should not keep us from addressing it, as it plays a key role in the institutional dynamism which to an important extent influences the outcomes of governmentinduced change in the higher education system.

\section{Concluding remarks}

By identifying four relationships which we consider important in addressing policy change and its outcomes, we have tried to demonstrate that a framework is needed in which system change is approached as a multi-level phenomenon. To borrow from some earlier work (Meek and Goedegebuure 1989b), change is often analyzed in terms of power available to one actor (mostly government) to impose its will on others (the institutions) despite opposition. We propose a somewhat different theoretical view of change: the degree and extent of change in a complex system such as higher education, are dependent upon the interaction of interests, strategic behaviour, preferences, and ideologies of all involved. The more these factors tend to coincide or converge, the more likely it is that change will be extensive and ubiquitous. A view of change that concentrates on one group of people doing something to another group of people is too narrow. The question is not solely one of (state) intervention, but of how and why conditions prevail to the degree that 
extensive and far-reaching change becomes possible, or, on the other hand, why these conditions do not arise. The four level framework presented above in no way is complete or fool-proof. It can, however, hopefully, be of use in focusing attention on the conditions and relationships that play a central role in change in higher education systems.

\section{Notes}

I. For a discussion on the development of quality assessment systems in the Netherlands, see Goedegebuure, Maassen, and Westerheijden 1990.

2. According to Friedrich's law of anticipated consequences, however, it is to be expected that the Ministry reckons with the opinion of the parliamentary majority.

3. A higher education lobby does exist in the Netherlands, certainly with respect to denominational and agricultural institutions (see Goedegebuure and Vos 1988, regarding the HBO-sector).

4. Of course, this is not true for the direct market relationships that exist in the areas of contract teaching and contract research. However, this is but a minor part of the higher education budget.

5. It should be noted that Dutch students by and large do not make their choice for an institution on the basis of quality arguments, but on geographical location.

6. Data obtained from a preliminary analysis of HBO-development plans.

7. The description of the relations in universities are geared to the European, and more specifically the Dutch, situation, rather than the American situation. For a comparison, see Clark 1983.

8. In Kogan's words: 'without active academics securing the reputation of the institution the managers would have nothing worthwhile to manage. There is, therefore, a process of exchange between those who manage and those who provide the main academic outputs of the institutions. They provide the expertise upon which the institution thrives or fails. The institution provides the resources enabling them to perform their academic tasks' (1984: 64).

\section{References}

Aldrich, H.E. (1979). Organizations and Environments. Englewood Cliffs: Prentice Hall.

Allison, G.T. (1971). Essence of Decision. Boston: Little, Brown \& Co.

Anderson, R.E. (1977). Strategic Policy Changes at Private Colleges. New York: Teachers College Press. Baldridge, J.V. et al. (1978). Policy Making and Effective Leadership. San Francisco: Jossey Bass.

Becher, T. and Kogan, M. (1980). Process and Structure in Higher Education. London: Heinemann.

Benson, J.K. (1975). 'The interorganisational network as a political economy', Administrative Science Quarterly 20, 229-249.

Bijleveld, R.J. (1989). 'The two tier structure in university education', in Maassen, P.A.M. and Van Vught, F.A. (eds.), Dutch Higher Education in Transition. Culemborg: Lemma, pp. 29-46.

Bijleveld, R.J. and Goedegebuure, L.C.J. (1989). 'The paralysing effects of a balanced power system', in Maassen, P.A.M. and Van Vught, F.A. (eds.), Dutch Higher Education in Transition, Culemborg: Lemma, pp. 99-110.

Binsbergen, P. and H. De Boer (1988). Hoger Onderwijs in de Jaren Negentig. Enschede: CHEPS.

Birnbaum, R. (1983). Maintaining Diversity in Higher Education. San Francisco: Jossey-Bass.

Blau, P. (1964). Exchange and Power in Social Life. New York: Wiley \& Sons.

Boorsma, P.B. and Koelman, J.B.J. (1986). 'Retrenchment policy in the Dutch university systern: the case TVC', International Journal of Institutional Management in Higher Education 1, 62-75.

Cerych, L. and P. Sabatier, P. (1986). Great Expectations and Mixed Performance. Stoke-on-Trent: European Institute of Education and Social Policy/Trentham Books.

Clark, B.R. (1983). The Higher Education System: Academic Organization in Cross-National Perspective. 
Berkeley: University of California Press.

De Alessi, L. 1983. 'Property rights, transaction costs and x-efficiency: an essay in economic theory', American Economic Review 73, 64-81.

DiMaggio, Paul J. and Powell, Walter W. (1983). 'The iron cage revisited: institutional isomorphism and collective rationality in organizational fields', American Sociological Review 48 (April), 147-160.

Goedegebuure, L.C.J. (1989). 'Institutional mergers and system change', in Maassen, P.A.M. and Van Vught, F.A. (eds.), Dutch Higher Education in Transition. Culemborg: Lemma, pp. 71-110.

Goedegebuure, L.C.J., Maassen, P.A.M. and Westerheijden, D.F. (eds.) (1990). Peer Review and Performance Indicators. Culemborg: Lemma.

Goedegebuure, L.C.J. and Vos, H.J. (1988). Herstructurering van het Hoger Beroepsonderwijs; de Operatie STC/HBO. Zoetermeer: Ministerie van Onderwijs en Wetenschappen.

Green, T.F. (1980). Predicting the Behavior of the Educational System. Syracuse University Press.

Groot, H. De and J.M.M. Ritzen, J.M.M. (1988). Lessen in Bezuinigen. Zoetermeer: Ministerie van Onderwijs en Wetenschappen.

Hodgkinson, H.L. (1971). Institutions in Transition. New York: McGraw-Hill.

Kaiser, F., Koelman, J.B.J., Florax, R.J.G.M., van Vught, F.A. (1991). Public Expenditure on Higher Education; A Comparative Study in the EC-Member States, 1975-1988. Enschede: CHEPS.

Kogan, Maurice (1984). 'The political view', in Clark, B.R. (ed.), Perspectives on Higher Education. Berkeley: University of California Press, pp. 56-75.

Levine, S. and White, E. (1961). 'Exchange as a conceptual framework for the study of interorganizational relationships', Administrative Science Quarterly 5, 583-601.

Lieshout, R.H. (1984). Without Making Elaborate Calculations for the Future. Enschede.

Maassen, P.A.M. and Van Vught, F.A. (eds.)(1989). Dutch Higher Education in Transition: Policy-Issues in Higher Education in the Netherlands. Culemborg: Lemma.

Martin, W.B. (1969). Conformity: Standards and Change in Higher Education. San Francisco: Jossey-Bass.

Meek, V.L. (1988). 'Institutional mergers in Australian higher education', in Goedegebuure, L.C.J. and Meek, V.L. (eds.), Change in Higher Education: The Non-university Sector. An International Perspective. Culemborg: Lemma, pp. 85-110.

Meek, V.L. and Goedegebuure, L.C.J. (1989a). Higher Education: A Report. Armidale: University of New England.

Mcek, V.L. and Goedegebuure, L.C.J. (1989b). 'Change in higher education. The Australian case', Australian Educational Researcher 16(4), 1-15.

Millet, J.D. (1976). Mergers in Higher Education: An Analysis of Ten Case Studies. Washington DC: The American Council on Education.

Ministry of Education and Science (1983). Schaal-Vergroting, Taakverdeling en Concentratie in het Jloger Beroepsonderwijs (STC-document). "s-Gravenhage: SPO.

Ministry of Education and Science (1985). Hoger Onderwijs; Autonomie en Kwaliteit (HOAKdocument). Zoetermeer: SPO.

Ministry of Education and Science (1988). Higher Education and Research Plan (HOOP). Zoetermeer: Fciten \& Cijfers.

Ministry of Education and Science (1990). Higher Education and Reseurch Plan (HOOP). Zoetermeer: Feiten \& Cijfers.

Moe, T. (1984). 'The new economics of organization', American Journal of Political Science 28, 739-777.

Neave, G. (1983). 'The dynamics of integration in non-intcgrated systems of higher education in Western Europe', in Hermanns, H., Teichler, U. and Wasser, H. (eds.), The Compleat University. Cambridge, Mass.: Schenkman, pp. 263-276.

Niskanen, W.A. (1971). Bureaucracy and Representative Government. Chicago: University Press.

Pfeffer, J. and Salancik. G. (1978). The External Control of Organizations. New York: Harper \& Row. Rourke, F.E. (1969). Bureaucracy, Politics, and Public Policy. Boston: Little, Brown \& Co.

Scharpf, F.W. (1978). 'Interorganizational policy studies: issues, concepts and perspectives', in Hanf, K. and Scharpf, F.W. (eds.), Interorganizational Policymaking. London: Sage, pp. 345-371.

Spaapen, et al. (1988). Evaluatie Vijf Jaar Voorwaardelijke Financiering. Zoetermeer: Ministeric van Onderwijs en Wetenschappen. 
Teichler, U. (1986). The Changing Role of Non-University Higher Education in Comparative Perspective. Wassenaar: NIAS.

Teichler, Ulrich (1988). Changing Patterns of the Higher Education System. London: Jessica Kingsley. Vries de, P. (ed.) (1990). Bekostiging en Doelmatigheid in het Hoger Onderwijs. Utrecht: Lemma.

Vroeijenstijn, A.I. and Acherman, H. (1990). 'Control oriented versus improvement oriented quality assessment', in Goedegebuure, L.C.J., Maassen, P.A.M. and Westerheijden, D.F. (eds.), Peer Review and Performance Indicators. Culemborg: Lemma, pp. 81-101.

Van Vught, F.A. (1985). 'Negative incentive steering in a policy network', Higher Education 14, 593-616. Van Vught, F.A. (ed.) (1989). Governmental Strategies and Innovation in Higher Education. London: Jessica Kingsley.

Westerheijden, D.F. (1988). Schuiven in de Oosterschelde: Bes/uitvorming rond de Oosterschelde 19731976 [Gates in the Eastern Scheldt: Decision-Making Concerning the Eastern Scheldt 1973-1976]. Enschede: Twente University.

Westerheijden, D.F. (1990a). 'Peers, performance and power', in Goedegebuure, L.C.J., Maassen, P.A.M. and Westerheijden, D.F. (eds.), Peer Review and Performance Indicators. Culemborg: Lemma, pp. 183-207.

Westerheijden, D.F. (1990b). 'Quality and power'. Paper presented to the 12th Annual EAIR Forum, Lyon. September 9-12.

Whitley, R. (1984). The Intellectual and Sacial Organization of the Sciences. Oxford: Clarendon Press. 